\title{
Ten tips for writing a book
}

\author{
Ellis Royston \\ Author \\ Journal of the Ceylon College of Physicians, 2015, 46, 58
}

When British author and long-term Sri Lanka resident, Royston Ellis, addressed the College of Physicians in one of the "Beyond Medicine" lectures in May 2015, he suggested the following tips on writing a book.

To be a writer requires a dedication and discipline that few people have. Luckily, it can be learned, as can all the techniques necessary to write.

Here are my TEN TIPS to follow if you aspire to be a writer.

1. Stop aspiring and get on with it. Don't dream about being a writer and think how wonderful it must be. Don't daydream about the story you are sure you can write. Get on with it!

2. How? Start by reading. No one can write without reading. Don't use the excuse: "I don't want to be influenced by other writers. Read everything from newspaper columnists to the classics, from drivel to the inspired.

3. Buy books. Writers need people to buy their books, so get into the habit of buying books. Build up a mini library of books so you create the right atmosphere for writing.

4. Buy a good dictionary and dip into it every day. Buy a copy of Roget's Thesaurus and read it when you have spare moments. This helps you learn about the power and beauty of words.

5. Be young. As a young person you have a great curiosity about life and are more of a slave to your passions than an older person. If you are no longer young then make sure your enthusiasm is propelled by your heart, not your head. You need emotion not calculation to write well.

6. Write poetry. By writing poetry you will learn the value of words and discipline in their usage. The advantage is that a poem is short and won't take so long to write as a short story or a book chapter.

7. Set a particular period each day for writing. Keep at it from the same time every day.

8. Set a minimum target of the number of words you want to write in a day or a week, and don't give up until you have hit that target.

9. When you've written something you are proud of, lose it for a week. Then look at it again. It won't be as good as you thought. Write it again, and lose it again. Re-read it after another week and improve it - or throw it away and start again.

10. Plan each day's writing in advance. When you go to bed at night, think about what you want to write the next day. Your brain will work on it while you're asleep and the next day the words will flow. Then lose it (see Tip Number 9). 